\title{
EREBEA
}

Revista de Humanidades y Ciencias Sociales

Núm. 9 (2019), pp. 161-188

ISSN: 0214-0691

http://dx.doi.org/10.33776/erebea.v9i0.3694

\section{EL SECANO MEJORADO Y LA AGRICULTURA ATERRAZADA. PAISAJES SIGNIFICATIVOS CON UN GRAN VALOR SOCIO-AMBIENTAL Y DIDÁCTICO ${ }^{\mathrm{I}}$}

\author{
María Hernández-Hernández \\ Universidad de Alicante \\ Álvaro Fco. Morote Seguido \\ Universidad de Valencia \\ Enrique Moltó Mantero \\ Universidad de Alicante
}

RESUMEN

En los últimos veinte años, en las denominadas sociedades postproductivistas se ha producido un redescubrimiento del paisaje asociado a su identificación como un elemento identitario y de calidad. En la provincia de Alicante, representativos resultan el denominado secano mejorado (aprovechamiento de turbias) característico de la comarca de l'Alacantí y los paisajes aterrazados (Montaña de Alicante). Los objetivos de esta investigación son: 1) Analizar la ordenación tradicional de los paisajes derivados del uso de turbias y los aterrazados; 2) Analizar las estrategias de adaptación al medio y cómo el proceso de abandono ha repercutido ambientalmente en el área de estudio; 3) Poner de manifiesto cómo estas estrategias tradicionales pueden contribuir a incrementar la resiliencia de los territorios frente a diferentes riesgos (inundación, deslizamientos, etc.); 3) Examinar los nuevos valores que los paisajes presentan en la sociedad actual, no solo desde el punto de vista funcional (relacionado con el turismo y agricultura), sino también con las funciones socio-ambientales y educativas

\section{ABSTRACT}

In the last twenty years, in the so-called post-productive societies there has been a rediscovery of landscapes associated with its identification as an identity and quality feature. In the province of Alicante, the improved dry farming (muddy waters) in the comarca of Alacantí and the terraced landscapes (Mountain of Alicante) are representative. The aims of this research are: 1) Analysis of the traditional management of the terraced landscapes and those derived from the use of muddy waters; 2) To analyse the coping strategies to the environment and how the abandonment of farming has had an environmental impact; 3) To highlight how these traditional strategies can contribute to increase the territories' resilience to different risks (floods, landslides, etc.); 3) To consider the new values that these landscapes present in today's societies, not only from the functional point of view (related to tourism and agriculture), but also with the socioenvironmental and educational functions that they perform; and 4) To develop didactic strategies from environmental education for understanding these 
que desempeñan; y 4) Elaborar estrategias didácticas desde la educación ambiental para la interpretación de estos paisajes significativos. Los resultados ponen de manifiesto que el proceso de valorización no ha sido paralelo al conocimiento de los elementos que caracterizan a los pasajes más allá de aproximaciones estereotipadas. Un mejor conocimiento de su génesis y funcionamiento contribuirá a fomentar su comprensión por la sociedad.

Palabras Clave

Paisaje, secano mejorado, paisaje aterrazado, didáctica, valor ambiental.

Fecha de recepción: 10 de noviembre de 2019

Fecha de aceptación: 5 de diciembre de 2019 significant landscapes. The results show that the process of valorisation has not been held in parallel to a process of knowledge of their elements beyond stereotyped approaches. A better knowledge of its origin and functioning will contribute to promote its understanding by the society.

KeYwORDS

Landscape, improved dry farming, terraced landscape, instruction, environmental value.. 


\section{i. ConteXtualizacion, justificación y Planteamento del estudio}

Desde finales del pasado siglo XX se ha producido un redescubrimiento del paisaje que se vincula con tres variables como son: 1) Su revalorización social al ser considerados como signo de identidad frente a la homogeneización y globalización de las dinámicas económicas recientes; 2) Su consideración como un recurso económico "nuevo"; y 3) La ordenación y gestión de las transformaciones que se producen en el territorio (Zoido, 2016; Mata, 2004) y el reencuentro de la sociedad civil con el lugar (Nogué, 2016). A la función productiva tradicional de proporcionar materias primas se une una nueva cualidad como es la de ofertar servicios, especialmente orientados al turismo. Esta nueva funcionalidad es contemplada y potenciada por las políticas agrarias comunitarias que se articulan a partir de la reforma McSharry y por las de desarrollo rural. Estas últimas, mediante la adopción de estrategias globales basadas en la multifuncionalidad de los medios rurales y la revalorización de sus recursos endógenos (patrimonio natural, paisajístico y cultural), se orientan a la diversificación de la economía de territorios con problemas de desarrollo para contribuir al mantenimiento de su población y paliar los desequilibrios territoriales que los caracterizan (Cebrián, 2000).

Estos nuevos planteamientos se ven reforzados desde la óptica institucional y normativa por la Convención Europea del Paisaje celebrada en Florencia en el año 2000 que considera que todo paisaje es objeto de atención y no sólo aquellos que gozan de un elevado reconocimiento bien por valores estéticos o ambientales. En palabras de Ojeda (2013), el discurso institucional contemporáneo preconiza una apertura de la consideración paisajística de lo elitista a lo democrático y una consecuente valoración de los paisajes cotidianos. Esta debe ser entendida no solo como signos del desarrollo contemporáneo de una comunidad humana que expresa en ellos su secular inteligencia compartida (Ojeda, 2015) y en los que se enlazan la estética, la ética y la política (Zoido, 2012), sino también como patrimonio, entendido como el reconocimiento social de unos valores y una herencia comunitaria (Mata, De Meer y De la Puente, 2012).

Este descubrimiento y revalorización del paisaje ha generado notables aspectos positivos, sin embargo, todavía hoy permanecen numerosas sombras. Algunas de estas cabe relacionarlas con el proceso de comprensión del paisaje como un elemento integrado y resultado de las dinámicas y procesos que lo han generado, 
más allá de los aspectos formales y visuales. Hablar acerca del concepto de paisaje es una labor compleja por la propia definición del mismo. Hernández (2009) argumenta que es el resultado de la combinación de aspectos diversos, como son los naturales, los históricos y los funcionales, pero también adquiere valor simbólico y subjetivo al ser considerado reflejo de la herencia cultural de un pueblo, de su identidad y resultado de unas prácticas históricas ejercidas por un grupo humano sobre el territorio.

En este trabajo se analizarán dos tipologías de paisajes significativos del territorio alicantino a modo de estudio de caso, pero extrapolables a ámbitos nacionales e internacionales, a saber, el paisaje rural del denominado "secano mejorado" y "el paisaje aterrazado". En ambos, el elemento definidor es la adopción de una particular ordenación que va a permitir minimizar una serie de elementos negativos (por ejemplo, la irregularidad de precipitaciones -escasas y de fuerte intensidad horaria- y la de horizontes edáficos poco desarrollados).

Respecto al primer tipo de paisaje, la falta de agua guio las actuaciones antrópicas que se sintetizaban en una doble aptitud. Por un lado, buscar los medios para aprovechar las lluvias, generalmente concentradas en unos cuantos episodios del otońo y la primavera. Y por otro, controlar su capacidad erosiva sobre los suelos. El riego se convierte, por tanto, en una necesidad para asegurar unos rendimientos adecuados de los cultivos, pero también para poder aprovechar al máximo los escasos recursos hídricos disponibles. Donde la irrigación continua no es posible, se mejora la humedad del suelo, concentrando el agua de lluvia en unas cuantas parcelas seleccionadas, configurándose unos paisajes a partir del uso de las aguas de escorrentía, también denominado riego de turbias (Morales, 1969), inundación dirigida (Mongil, Martínez de Azagra, Sánchez y García, 2009) o secano mejorado (López Gómez, 1951). Se trata de un tipo de aprovechamiento intermedio entre el secano y el regadío, ya que esos mayores aportes hídricos permitían reducir la aleatoriedad del primero, pero en ningún caso consentían el desarrollo de cultivos de regadío en sentido estricto. La adopción de esta práctica, según los primeros estudiosos franceses de inicios del siglo XX, es de procedencia mesopotámica. Sin embargo, para la cuenca del Mediterráneo se ha señalado a los romanos como sus difusores, pues algunas presas de derivación de aguas de avenida tienen restos de mampostería romana o están asociadas a centuriaciones (Morales, 1974). Sin embargo, va a ser en el siglo XVIII cuando se produzca un significativo aumento de las superficies beneficiadas con este sistema de riego, resultado, en gran medida, del incremento poblacional y la roturación de nuevos espacios agrícolas y el empleo de nuevas técnicas. La aparición de técnicas similares en diversos continentes lo resuelve Palerm (2002: 13) indicando que son fruto "de invenciones independientes, resultado de soluciones a la misma problemática; de la misma forma que la conducción del agua por canales es una invención independiente en regiones muy diversas". La cuestión no es baladí 
cuando esta organización viene a representar un proceso de antropización del medio de considerable extensión y de milenaria historia que ha sido objeto de estudio desde una óptica academicista desde la primera mitad del siglo XX (Morales y Hernández, 2018).

La relación entre la sociedad y el medio también se hace patente en el segundo paisaje significativo objeto de análisis. En las áreas de montaña, los condicionantes físicos obligaron a la adopción de una particular sistematización, el abancalamiento de sus laderas, constituyendo, además, su rasgo más distintivo. En estos territorios, además de los factores físicos, concurren otros relacionados con sus pobladores, que resultan no menos decisivos. Entre los condicionamientos humanos, destaca la presión demográfica como una constante que implicaba una demanda creciente de la superficie cultivada, a costa de interfluvios o piedemontes que, en ocasiones, presentan pendientes en torno a 20 o $30^{\circ}$. En unas civilizaciones con escasa tecnología disponible, el incremento de la producción sólo se logra cultivando nuevas tierras. Este proceso alcanza cotas insospechadas en el siglo XVIII. Se ponen, de este modo, en cultivo áreas de montańa hasta altitudes que, en ocasiones, se sitúan próximas al umbral ecológico de los cultivos, cuando no lo superan (Hernández, 2010; Giménez, 2016). Representativos son los paisajes de Cinque Terre (Liguria), del valle del Chianti o Val d'Elsa en Toscana, los Cevennes franceses, las montañas del interior de Alicante o Castellón (Comunidad Valenciana), entre otros muchos ejemplos.

Desde mediados del pasado siglo XX se ha producido un abandono de estos paisajes por diferentes motivos. En primer lugar, el paso de una sociedad agraria a una de base industrial y posteriormente de servicios con la consiguiente pérdida de relevancia económica de esta actividad y de activos (Lasanta, 2007). Un segundo factor es el escaso rendimiento de la agricultura practicada en estos paisajes; sin olvidar, la dificultad de disponer de recursos hídricos. El abandono de las prácticas agrícolas, la pérdida de activos y la simplificación de numerosas tareas debido a la escasa rentabilidad de los aprovechamientos agrícolas se han traducido en la degradación de unos paisajes de gran valor no solo cultural (Asins, 2007), sino también en términos de biodiversidad (Klein, Baquero y Clough, 2006), y en la reactivación de procesos erosivos (incrementos de ondas de crecida de las escorrentías, etc.), que estas ordenaciones minimizaban (Moltó y Hernández, 2012).

Respecto al ámbito educativo, la importancia que tienen los paisajes en términos de calidad de vida y de cultura, los procesos de degradación que afectan a muchos de ellos, así como la creciente demanda de especialistas en su protección, gestión y ordenación son razones suficientes para que los docentes hagan llegar al alumnado los conocimientos más recientes en torno a este concepto. Sin embargo, la posición clásica ha hecho más incidencia en los aspectos descriptivos y visuales que en otros componentes del mismo como es su multifuncionalidad, las 
políticas públicas ante los recursos finitos o la convivencia con los desequilibrios socio-ambientales. Es necesario superar las concepciones trasnochadas de paisajes naturales y paisajes antrópicos para poder valorar los elementos de transformación cultural del ambiente (Souto, 2007).

Respecto a la enseñanza del paisaje en los diferentes niveles educativos (Infantil, Primaria, Secundaria y Bachillerato) cabe destacar que esta temática se debe trabajar en las clases de Ciencias Sociales y Geografía, como ponen de manifiesto los Reales Decretos que establecen los contenidos mínimos y donde aparece referenciado el paisaje o los contenidos relativos al mismo: Real Decreto 1630/2006, de 29 de diciembre, por el que se establecen las enseñanzas mínimas del segundo ciclo de Educación infantil; Real Decreto 123/2014, de 28 de febrero, por el que se establece el currículo básico de la Educación Primaria; y Real Decreto 1105/2014, de 26 de diciembre, por el que se establece el currículo básico de la Educación Secundaria Obligatoria y del Bachillerato.

Una de las potencialidades que permite la Geografía es que posibilita realizar numerosas actividades fuera del aula que se pueden utilizar como activadores de aprendizaje y de motivación para aprender. De estas, numerosos autores han resaltado el indiscutible potencial didáctico del trabajo de campo (Delgado y Rodrigo, 2012; Álvarez, Vásquez y Rodríguez, 2016; Arias, Gómez y Martínez, 2016; Fernández, 2017). La visita al espacio geográfico puede y debe considerarse la mejor herramienta para interpretar, conocer y analizar un territorio. Solo a través del análisis vivencial se puede comprender el papel que desempeñan las partes en el conjunto e identificar las relaciones que se establecen entre los elementos que configuran un paisaje.

La hipótesis de partida de esta investigación ensayística es que a pesar de la revalorización que han registrado los paisajes, la sociedad en general muestra un significativo desconocimiento de los procesos y dinámicas que los generaron y que es necesario mantener para preservarlos. Por tanto, la sociedad y en especial las cohortes más jóvenes deben aprender, entender e interpretar el territorio mediante estrategias didácticas eficaces y desarrolladas en el medio. El problema de investigación se articulará, por tanto, en torno a la idea de incrementar el conocimiento sobre estos paisajes a través de la educación ambiental. En ese sentido, los objetivos de esta investigación son: 1) Analizar la ordenación tradicional de los paisajes derivados del uso de turbias y los aterrazados; 2) Analizar las estrategias de adaptación al medio y cómo el proceso de abandono ha repercutido ambientalmente en el área de estudio; 3) Poner de manifiesto cómo estas estrategias tradicionales pueden contribuir a incrementar la resiliencia de los territorios frente a diferentes riesgos (inundación, deslizamientos, etc.); 4) Examinar los nuevos valores que los paisajes presentan en la sociedad actual, no solo desde el punto de vista funcional (relacionado con el turismo y agricultura), sino también con las funciones socio-ambientales y educativas que desempeñan; 
y 5) Elaborar estrategias didácticas desde la educación ambiental para la interpretación de estos paisajes significativos.

Para la consecución de los objetivos propuestos se han aplicado, dos tipos de acciones, por un lado, aquellas conducentes a analizar y profundizar en el funcionamiento y procesos que caracterizan a estos paisajes significativos (objetivos 1, 2, 3 y 4) y, por otro, elaborar propuestas didácticas (objetivo 5), concretamente, salidas de campo que revelen su potencial didáctico.

En la primera se ha llevado cabo una revisión bibliográfica sobre estos paisajes. Para ello se ha realizado una búsqueda en bases de datos sociales y concretamente la del ISOC (CSIC) y puntualmente en otras bases de datos (GEOBASE y REDALyC). Se han examinado, asimismo, las revistas de Geografía reunidas en el catálogo de bibliotecas universitarias (REBIUN) y el portal de difusión de producción científica DIALNET. La explotación de estas fuentes documentales se llevó a cabo a través de una serie de criterios de búsqueda (palabras clave): turbias, secano mejorado, boquera, paisaje aterrazado, abancalamiento, agricultura y Alicante. No obstante, cabe indicar que no se pretende llevar a cabo un estado de la cuestión, sino identificar aquellas publicaciones que son referentes sobre esta temática en el área de estudio y que permitan identificar los procesos y las dinámicas que los definen.

La segunda acción tiene como finalidad, a partir de la información recabada, poner de manifiesto el potencial didáctico de estos paisajes. La elaboración y realización de diversas salidas de campo permitirán (a través del análisis de diversos materiales y visita in situ donde se reflejen los elementos objeto de estudio) reconocer los factores que los configuraron, sus dinámicas, la incidencia social y ambiental de su desarticulación, etc. El aprendizaje vivencial permitirá aumentar el conocimiento y la capacidad de interpretación de estos paisajes y los problemas socio-ambientales actuales (riesgos naturales) que les afectan. Para ello se sintetizan algunas de las salidas de campo que se realizan en el Máster en Planificación y Gestión de Riesgos Naturales de la Universidad de Alicante en el área de estudio (Figura 1):

1. Salida de campo de la Huerta de Alicante, barranco del Juncaret y Parque La Marjal (asignatura 38822, Riesgos Naturales y Ordenación del Territorio). En ella se examinan los procesos de desorganización de antiguos secanos mejorados, su posterior urbanización y los efectos desde el punto de vista del riesgo de inundación y las políticas de ordenación del territorio adoptadas.

2. Salida de Campo en San Vicente del Raspeig y alrededores del campus de la Universidad de Alicante (asignatura 38804, Cambio climático y riesgo en el Mediterráneo), donde se analizan los procesos de desorganización del secano mejorado y los procesos de inundación, acentuados por los 
cambios en los usos del suelo, la deficiente praxis de urbanización y la intensificación de las precipitaciones.

3. Salida de campo a la Montańa de Alicante (asignatura 38818, Riesgos de causa atmosférica y climática), donde se analizan, entre otros, los efectos de erosión e inundaciones asociados a la pérdida de laminación de los espacios abancalados.
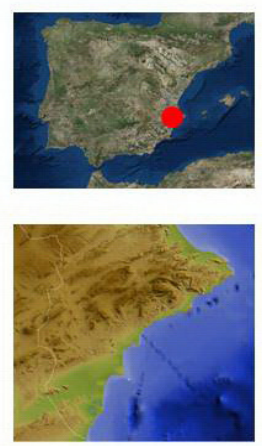

1. Huerta de Alicante

2. San Vicente del Raspeig y Campus Universitario

3. Montaña de Alicante

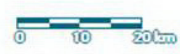

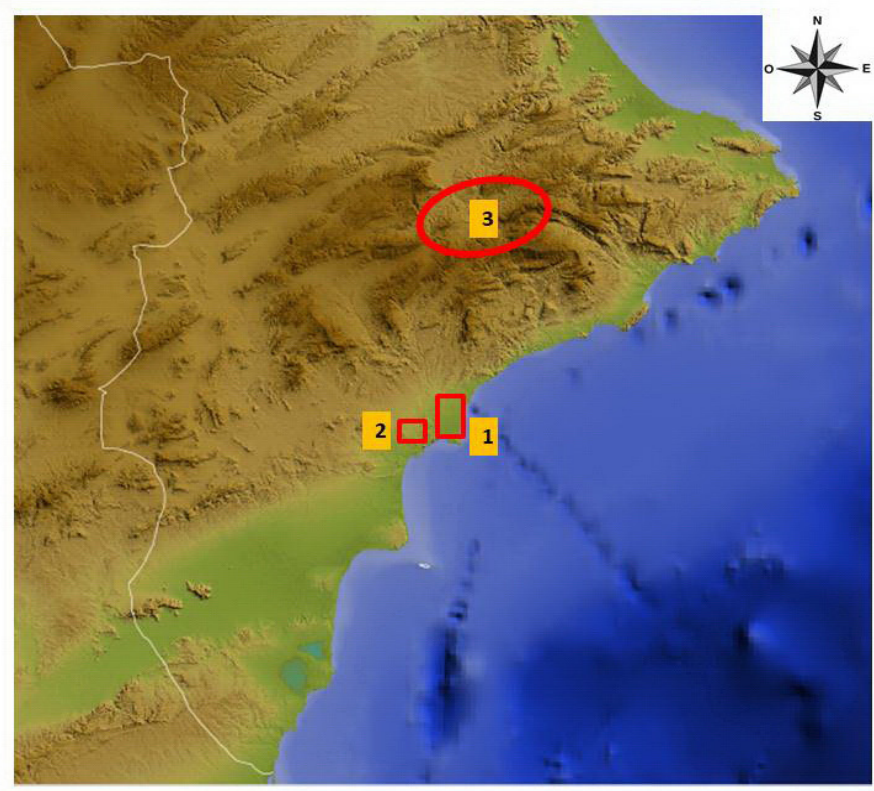

Figura 1. Área de estudio donde se realizan las salidas de campo propuestas (provincia de Alicante). Elaboración propia.

\section{RAsGos geográficos de LoS PAISAJES ANALIZAdos}

\subsection{EL SECANO MEJORADO. UN PAISAJE OLVIDADO}

\subsubsection{CARACTERÍSTICAS Y RASGOS DEFINIDORES DEL PAISAJE}

En España, el paisaje donde se practicaba el aprovechamiento de turbias se circunscribe a ámbitos áridos y semiáridos del sureste de la península ibérica. En estas tierras representan el sistema más extendido para la conservación del suelo y el agua, dos elementos escasos e imprescindibles para el desarrollo de la agricultura de secano (Morales y Box, 1996). El agricultor, para minimizar los rasgos citados, ideó una sistematización del territorio que es el resultado de una doble necesidad. Por un lado, disponer de tierras para el cultivo y suministrar a las mismas caudales al menos en una cantidad que permita asegurar las cosechas, 
lo que no siempre resultaba factible. Ello fue posible mediante la adopción de sistemas que permitían captar los volúmenes circulantes por las ramblas y barrancos coincidiendo con aguaceros copiosos. Y por otro, la retención de la escasa humedad derivada de las lluvias caídas directamente sobre las parcelas o superficies aledańas a ellas a mayor cuota altimétrica. Mediante la inducción y "recolección" de la escorrentía que discurre por las laderas, vertientes y cauces, se lograba almacenar la máxima cantidad de agua que fuera posible en el suelo durante los meses relativamente húmedos (otońo y primavera). Laderas, vertientes, lomas, barrancos y cauces fueron organizados y ordenados de manera que las escorrentías se pudieran conducir y derivar hacia las parcelas de cultivo situadas en cotas inferiores. La finalidad última era lograr aprovechar al máximo cualquier escorrentía coincidiendo con episodios de precipitaciones.

$\mathrm{Si}$ bien se pueden distinguir varios tipos de sistemas de aprovechamiento de turbias (Morales, 1969; Mondéjar, 2010; Hernández y Morales, 2013), el que presenta un mayor nivel de desarrollo y complejidad es el que consiste en la instalación, en el lecho de las ramblas y barrancos, de una presa generalmente de mampostería que provoca la interceptación de una parte de la arroyada, la cual era desviada hacia un canal lateral al que se denomina boquera (Morales y Box, 1986; López Bermúdez, 2014; Gil, López Fernández y Gómez, 2015) (figura 2). Su distribución, una vez extraídas del cauce fluvial, se realizaba mediante una red cuya complejidad dependía de la importancia de la superficie a regar. Posteriormente, mediante la realización de diversas labores del suelo, se reducía la evapotranspiración por capilaridad. De este modo, se conseguía conservar la mayor cantidad posible de humedad y durante el máximo tiempo posible en los perfiles profundos del suelo e incrementar las disponibilidades hídricas para los cultivos.

Figura 2. Paraje de La Revuelta (Agost), ejemplo un secano mejorado, donde, a partir de varias presas en el lecho del barranco, una que permitía la colmatación y construcción de bancales (1) y otra derivación de caudales (5) se crearon nuevos espacios de cultivo mediante pequeñas terrazas en el lecho de barrancos. Fuente: Morales y Box, 1986:19.

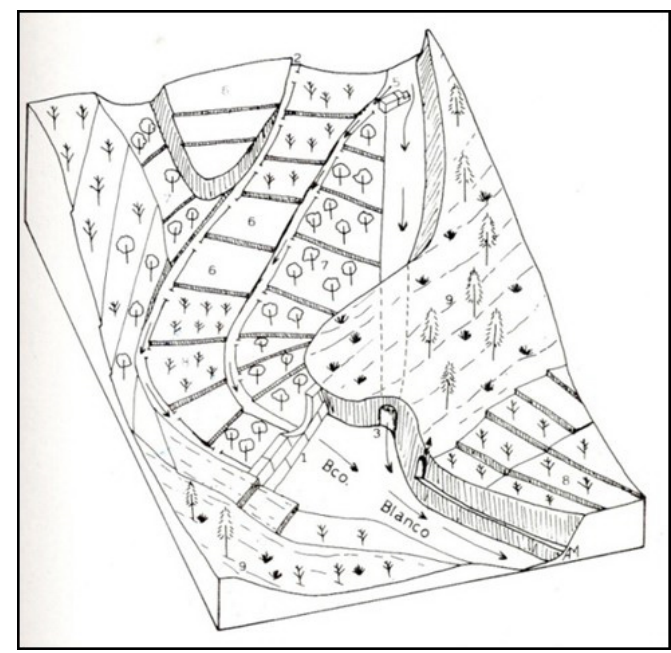




\subsubsection{BENEFICIOS AMBIENTALES ASOCIADOS A ESTAS TÉCNICAS Y EFECTOS}

\section{NEGATIVOS VINCULADOS A SU ABANDONO}

El aprovechamiento de turbias va a registrar un progresivo abandono a partir de mediados del siglo XX. Hernández, Saurí y Moltó (2016) asocian esta desarticulación a varios factores. Por un lado, a la baja rentabilidad de los cultivos de secano que no pudieron resistir la competencia salarial surgida en la costa, donde se instalan actividades secundarias y terciarias, así como áreas de cultivo de regadío de elevada cotización en los mercados. Por otro, a la posibilidad de disponer de mayores volúmenes de agua a través de la regulación de las escasas disponibilidades autóctonas, la obtención de aportes subterráneos gracias a la utilización de bombas de gran capacidad o las procedentes de otras cuencas.

Los beneficios que conllevaba la utilización de los aprovechamientos de turbias eran diversos (Moltó y Hernández, 2012), a saber: 1) Se recargaban los acuíferos ya que se laminaban grandes extensiones de terreno; 2) Se reducía la erosión y se facilitaba la retención de sedimentos, ya que todo el espacio roturado estaba estructurado mediante un complejo sistema de abancalamientos que impedían el arrastre y pérdida de suelo en éstas áreas (Marco y Vera, 1988; Marco y Morales, 1995) (Figura 3); y 3) Se minimizaba el riesgo de inundación, pues gran parte del caudal circulante de las ramblas y vertientes se distribuía entre los cultivos con lo que se aminoraban los efectos destructivos de las avenidas fluviales en los tramos bajos (Pérez, 2008).

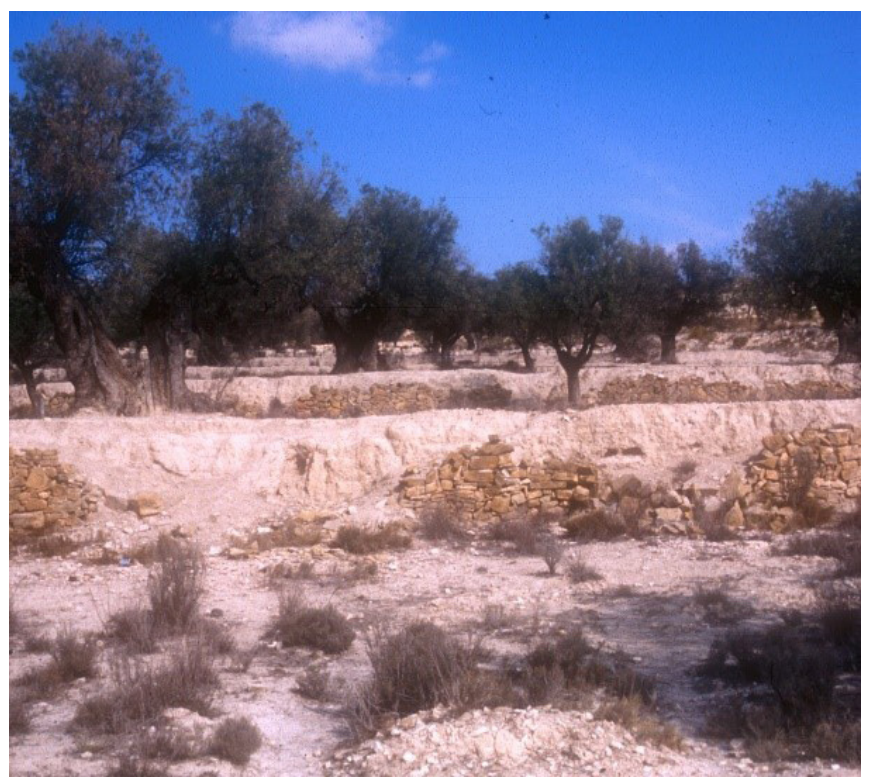

Figura 3. Proceso de desarticulación de las terrazas de cultivo e intensificación de los procesos erosivos en la cuenca del Barranco Blanco (Agost, Alicante). Foto: Autores, junio de 2014. 
El aprovechamiento de escorrentías y la laminación de agua de los cauces facilitaban un control de la torrencialidad y de los procesos de erosión hídrica. De manera que ahora, cuando se producen chubascos de fuerte intensidad horaria, la arroyada superficial se ve acelerada en relación a su funcionamiento en los siglos anteriores, provocando un aumento considerable de los caudales circulantes y potenciando la capacidad erosiva de estas ramblas (Morales, 1986). Las consecuencias de esta situación se han dejado notar no sólo allí donde estos fenómenos se han desencadenado, sino, como es lógico, también en las partes más bajas de las cuencas vertientes. Ilustrativo, por ejemplo, resulta el anegamiento de áreas urbanizadas y áreas de equipamientos y servicios en las proximidades de la Acequia del Gualeró, acequia mayor que distribuía las aguas de turbias derivadas a partir del azud de San Juan (Huerta de Alicante).

\subsubsection{REDESCUBRIMIENTO Y USOS POTENCIALES}

Hernández et al. (2016) ponen de manifiesto que estos sistemas han sido objeto de un interés creciente vinculado a cuestiones ambientales y paisajísticopatrimoniales desde finales del siglo XX. La conservación de suelo, la recarga de los acuíferos, la laminación de las ondas de crecida o el uso de estos caudales para hacer frente a los incendios o la repoblación forestal (Mongil y Martínez de Azagra, 2007) son algunos de los usos que actualmente abogan por su recuperación. A estos se une su utilización como recurso no convencional asociado a las políticas de sostenibilidad ambiental y de adecuación de la calidad de las aguas según su uso (fit for purpose) y contribuir a aumentar la resiliencia territorial ante episodios de incertidumbre hídrica generada por el cambio climático (Del Moral, 2009; Olcina, 2013). En este uso se inserta, por un lado, su utilización para usos urbanos (baldeo de calles, riego de jardines, etc.), que permitiría reducir la presión sobre el agua potable (Morote, 2013; Morote y Hernández, 2017) y, por otro, su uso con finalidad agrícola. Al respecto cabe mencionar la actuación que llevó a cabo en 1983 la empresa agrícola Bonnysa restaurando la boquera de la Casa de Berenguer en la Rambla del Vergeret (cuenca del Monnegre) para almacenar el agua en una balsa de riego o la derivación de caudales desde ramblas cercanas a los invernaderos para almacenar en balsas para su posterior uso para riego (Figura 4). Otro ejemplo es el caso de la actuación del IRYDA con la construcción en el Barranco del Vidre (Agost) de un dique conectado a una balsa de riego. 


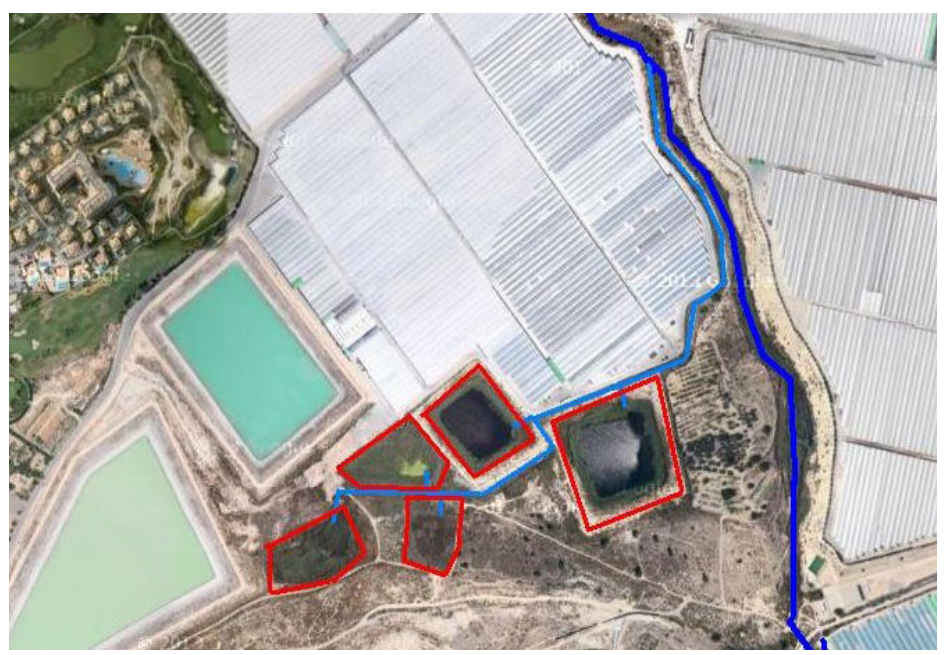

Figura 4. "Basses de Bonny". Sistema de recogida de pluviales para riego por parte de la empresa agrícola Bonnysa en el "Barranc del Fondó” (Mutxamel). Fuente: Morote, 2014.

\subsection{EL PAISAJE ATERRAZADO DE LA MONTANAA DE ALICANTE. UN PAISAJE AMENAZADO DE GRAN VALOR CULTURAL Y AMBIENTAL}

\subsubsection{CARACTERISTICAS Y RASGOS DEFINIDORES}

La cuenca mediterránea se presenta como un espacio orlado por montañas que han obstaculizado, tradicionalmente, la práctica agrícola debido a las dificultades orográficas que estas introducen (pendiente) y a las litologías dominantes (calizas y margas), que se traducen en suelos con horizontes edáficos poco desarrollados y fácilmente deleznables. Las condiciones climáticas tampoco eran óptimas para el desarrollo agrícola ya que, a pesar de la existencia de un gran número de microclimas, la característica más relevante son las precipitaciones escasas en el periodo estival cuando mayores son los requerimientos de las plantas y, a su vez, concentradas en el tiempo. Estas precipitaciones intensas unidas al factor pendiente generan notables procesos de pérdida de suelo. Estos factores, sin embargo, no fueron obstáculo para que las comunidades campesinas intentaran aprovechar económicamente este espacio. Fue, no obstante, necesario adoptar una ordenación específica, la construcción de terrazas (parcelas escalonadas con superficies horizontales o subhorizontales) que provocan una modificación de las pendientes y del flujo circulante por las mismas (figura 5). Esta ordenación de laderas, en ocasiones, se completa con sistemas de derivación de caudales desde torrentes y ramblas para crear suelos e incrementar la humedad del suelo (como se ha comentado anteriormente). 


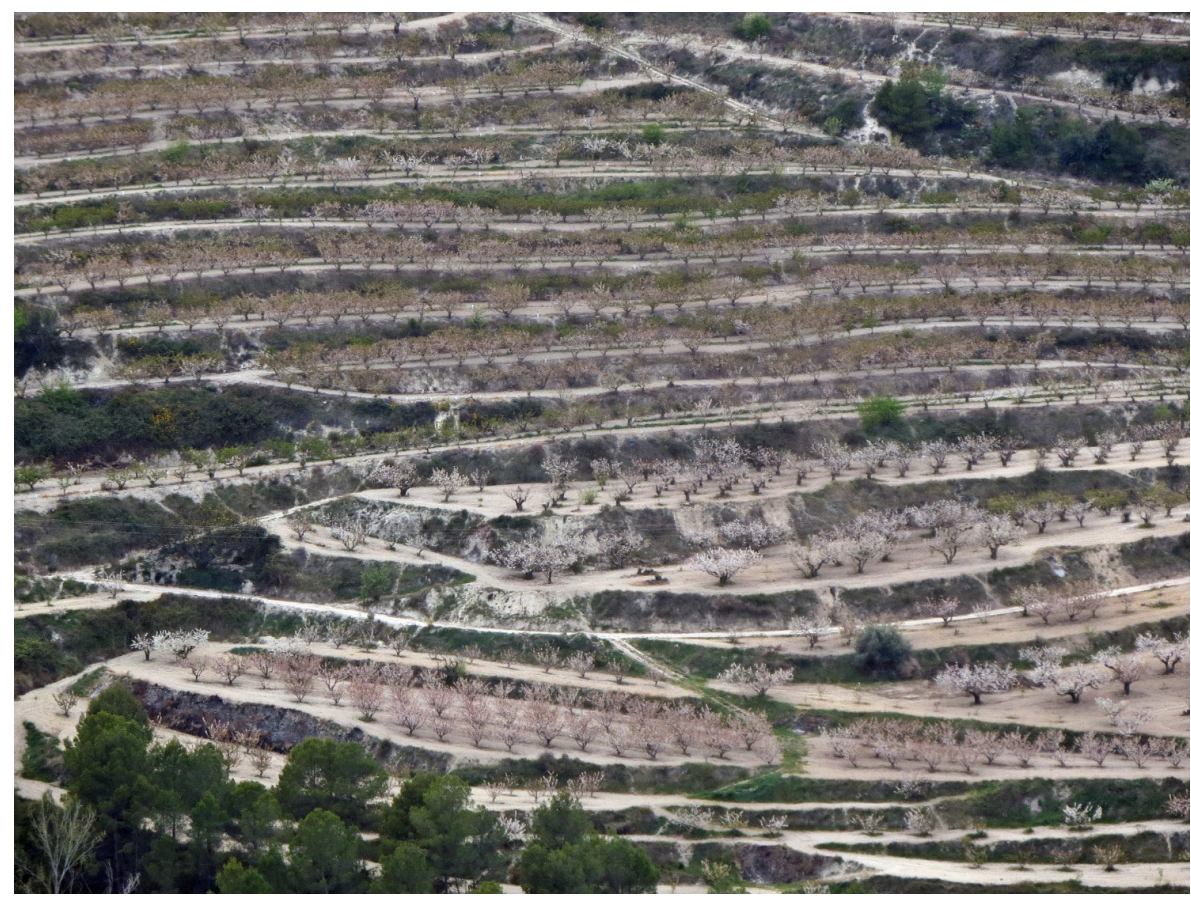

Figura 5. Paisaje prototípico de la denominada Montaña de Alicante caracterizado por el abancalamiento de las laderas. Fuente: Autores, febrero de 2018.

\subsubsection{BENEFICIOS AMBIENTALES ASOCIADOS A ESTAS TÉCNICAS Y}

REPERCUSIONES NEGATIVAS TRAS SU ABANDONO

A los factores ya mencionados se unen rasgos específicos que determinan el abandono de las prácticas agrícolas. Las elevadas pendientes, la pobreza de los suelos, la baja productividad, etc. fueron algunos de los factores que obstaculizaron la introducción de una agricultura con nuevas orientaciones productivas en esta comarca de montańa. En el caso de la Montaña de Alicante, a falta de los datos que se puedan desprender del Censo Agrario de 2019, pueden resultar ilustrativas algunas cifras de la evolución en el intercensal 1999-2009, en el que se han perdido un total de 1.000 unidades de trabajo-año (UTA), un descenso del 30\%. En este espacio el $68,8 \%$ de las tierras eran consideradas como no labradas en 1999, 13 puntos más que la media provincial. En el censo de 2009 el porcentaje se elevó al $72 \%$, con una pérdida superior a las 2.700 ha. En más de la mitad de los municipios de este ámbito territorial los porcentajes de tierras no labradas son superiores al $50 \%$.

Su desarticulación se relaciona con la reducción de la presión antropogénica; es el proceso denominado degradación por subexplotación (Moltó y Hernández, 2012). La sociedad no solo ha jugado un papel fundamental en la creación de 
estos paisajes, sino también en su conservación. Su mantenimiento requiere la realización de tareas (por ejemplo, la reparación de los muretes tras cada episodio de lluvias), que no se realizan en la actualidad por falta de rentabilidad. La contracción de las tierras cultivadas, la reducción del número de activos, el envejecimiento de los que permanecen, etc. generan notables repercusiones en estos paisajes, a saber: 1) Tendencia hacia una simplificación de las tareas que, tradicionalmente, se realizaban para mantener estos paisajes, especialmente de aquellas que no generan ninguna rentabilidad para el propietario de las tierras; 2) Intensificación de los procesos erosivos (incisiones en los muretes, cárcavas, etc.), que se traducen en la movilización de los horizontes edáficos y el incremento de la pérdida de suelos; y 3) Regeneración de la cubierta vegetal cuyo grado de recubrimiento varía en función del periodo de tiempo transcurrido desde que dejaron de ser cultivados. Esta recuperación, a priori positiva, encubre un cierto peligro como es la proliferación de incendios, ya que en las primeras fases de colonización vegetal lo que predomina son las formaciones herbáceas, altamente combustibles. Este riesgo se ve acentuado por la pérdida de funcionalidad que los bosques desempeñaban en las sociedades de base agraria.

\subsubsection{REDESCUBRIMIENTO Y NUEVOS USOS}

Al descubrimiento del valor cultural y patrimonial (Colomar, 2002) de estos paisajes y su prestación de servicios hay que unir en la última década las propuestas vinculadas a la revalorización de las producciones locales y de proximidad. Frente a la intensidad y homogeneidad, se aboga por poner en valor variedades locales y productos insertos en las nuevas propuestas agroecológicas (Hernández, Moltó y Morote, 2018). Más allá de las iniciativas para desarrollar producción ecológica certificada, los Sistemas Participativos de Garantía (SPG) son un sistema alternativo a la certificación ecológica oficial, y están implantados en Europa, en países como Francia o España, y en otros países del mundo (Moltó y Hernández, 2018). Por ejemplo, un grupo de agricultores de la Cooperativa de Cocentaina (Alicante) acaban de constituir un SPG, con el fin de certificar su propia producción de aceite agroecológico básicamente para autoconsumo. Dicha producción se llevará a cabo libre de cualquier producto de síntesis, mediante unas prácticas $100 \%$ respetuosas con el medio, utilizando únicamente productos autorizados en agricultura ecológica. Esta cooperativa ha impulsado esta certificación debido a las dificultades que implica la certificación oficial para parcelas muy pequeñas, en una zona montańosa de agricultura aterrazada. En el mismo sentido, la iniciativa Microviñas (Muro d'Alcoi) pretende recuperar el cultivo del viñedo con pequeńas parcelas recuperadas buscando un equilibrio entre la sostenibilidad económica, ambiental y social del cultivo y apostando por la identidad cultural del minifundio en este espacio. 
A estas propuestas se unen las iniciativas para mantener el paisaje en las que el agricultor juega un papel fundamental. Su conservación se vincula al predominio de la agricultura a tiempo parcial. Las ayudas y subvenciones eran fundamentales en los primeros años del siglo XXI para compensar la irregularidad y la caída de los precios de la aceituna en un entorno minifundista como el del área de estudio y suponían, asimismo, un aliciente para el pequeño productor y un "seguro" de rentabilidad para todos. Sin embargo, desde 2012 el cambio en las políticas que regulan las subvenciones agrícolas (pago único) y su evolución real y prevista en los próximos ańos elimina, en gran medida, esa contribución. De hecho, no ha supuesto mucho más del 15\% del total de lo pagado por las cooperativas en 2018 ya que todos aquellos que no llegan a los 500 euros de subvención no pueden optar a estas ayudas. En la coyuntura actual y futura de la Política Agraria Común (PAC), con una clara apuesta por la agricultura profesional, un elevado porcentaje de los agricultores de esta comarca, alrededor de un 90\%, que no tienen esa visión comercial de la actividad agraria sino una dedicación parcial, centrada en el ocio y el autoconsumo, quedarán al margen de estas ayudas.

Por último, cabe mencionar aquellas iniciativas vinculadas a reconocer el valor patrimonial de estos paisajes. En esta línea cabe inscribir la declaración como patrimonio inmaterial de la UNESCO en 2018 del arte de construir muros en piedra seca, la "piedra en seco". El Comité de Salvaguardia del Patrimonio Cultural Inmaterial de la UNESCO consideró que "los muros de piedra seca desempeńan un papel esencial en la prevención de corrimientos de tierras, inundaciones y avalanchas".

3. El paisaje como recurso didáctico. Propuestas y experiencias fuera del AULA EN EL TERRITORIO ALICANTINO

\subsection{LA HUERTA DE ALICANTE}

La Huerta de Alicante corresponde a un espacio de regadío tradicional (desde época romana) configurado a partir de los aportes del río Monnegre y la construcción de varios azudes en su tramo medio (los de Mutxamel, San Juan y El Campello) para derivar los caudales circulantes coincidiendo con precipitaciones de fuerte intensidad horaria. Desde mediados del siglo XX, la proximidad a la ciudad de Alicante y al sector litoral determinó un intenso proceso de desarticulación de los usos agrarios y su sustitución por una urbanización difusa (Hernández, 2011). La salida de campo se articula en torno a dos itinerarios (Figura 6) relacionados con objetivos y problemáticas diversas. 


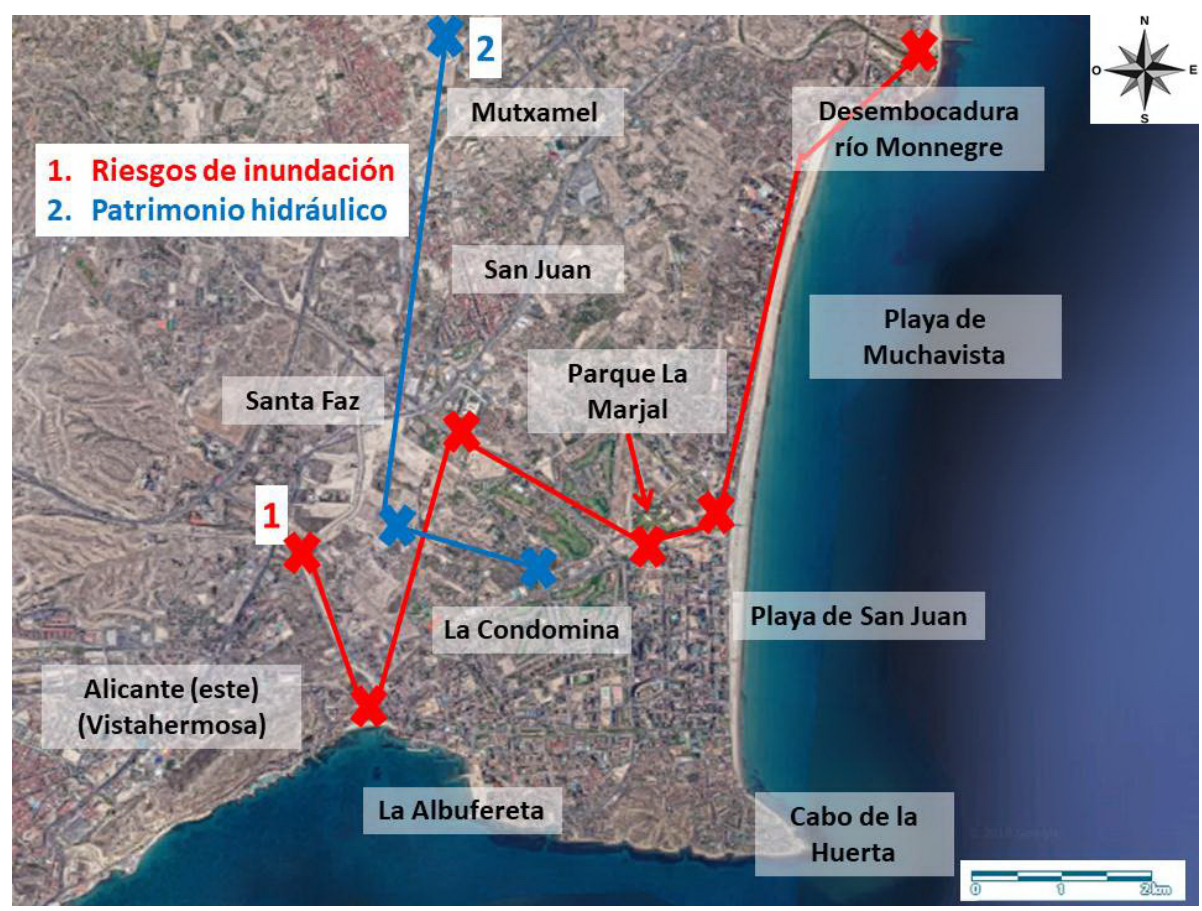

Figura 6. Itinerarios didácticos propuestos en la Huerta de Alicante. Elaboración propia

El primero (riesgo de inundación acentuado por los cambios de uso del suelo) se vincula con el análisis y cambio funcional de este espacio y los efectos desde el punto de vista del riesgo de inundación. Algunos de los puntos clave a visitar son los barrancos de Orgegia y Juncaret que fueron canalizados tras las riadas de 1997. Otros puntos a recorrer son algunas urbanizaciones que se han construido en zonas endorreicas (Playa de San Juan y Muchavista) o con problemas de anegamiento debido a la desarticulación de sistemas tradicionales de derivación de caudales (zona urbano-residencial del Hospital de San Juan), visita al Parque Inundable La Marjal (Morote, 2017) y la desembocadura del río Monnegre (El Campello).

La finalidad didáctica de esta salida de campo es múltiple ya que ayuda a comprender los procesos de inundación en ciertos espacios asociados a la urbanización de antiguos espacios agrícolas. Todo ello, relacionándolo con las características de las precipitaciones de este ámbito y la progresiva reducción de la capacidad de infiltración del suelo debido a su sellado y al abandono de las técnicas de derivación de caudales desde el río para regar este espacio agrícola, pero también para laminar las crecidas. La visita al parque La Marjal permite, por un lado, recrear un antiguo espacio lacustre que se constituye como una zona verde, además de servir para acumular caudales coincidiendo con precipitaciones 


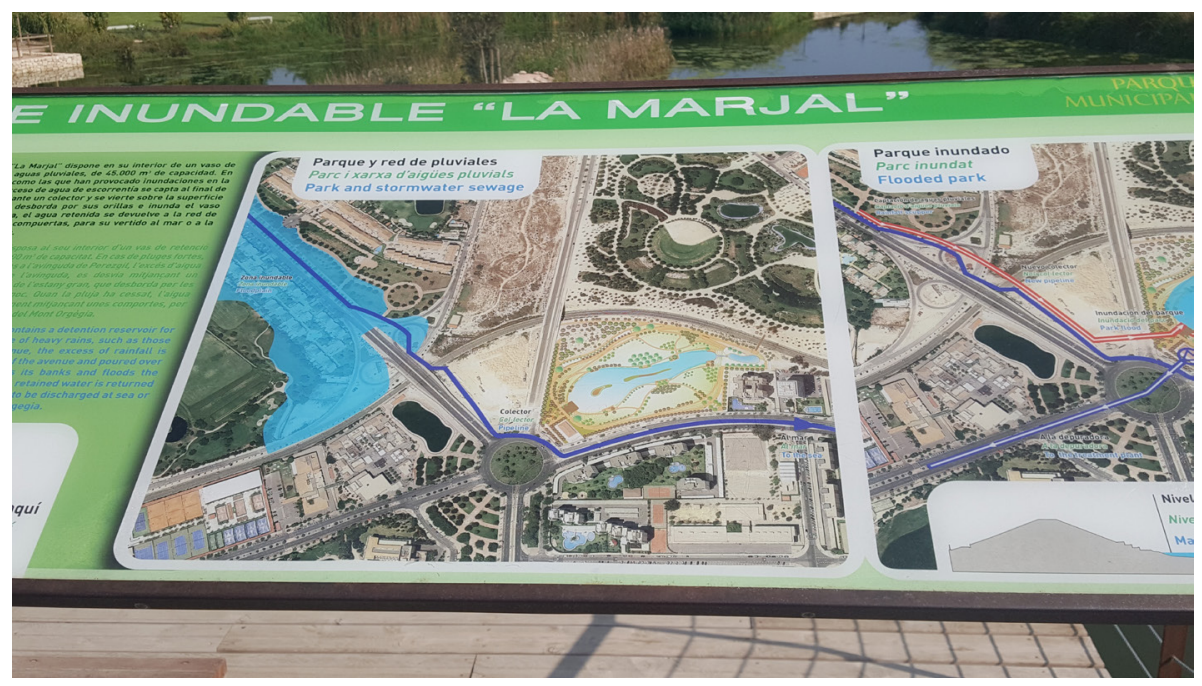

Figura 7. Panel explicativo del significado y funcionamiento del Parque La Marjal. Fotografía: Autores, octubre de 2016.

de fuerte intensidad, evitando inundaciones aguas arriba. Es un ejemplo claro de nuevo paradigma en la gestión del riesgo de inundación y uso de pluviales. Se trata de un espacio didáctico ya que en diferentes puntos se han instalado paneles informativos donde se explica la función de este parque (Figura 7). Con su realización, se desarrollan competencias y habilidades relativas a la percepción y experiencia sobre las inundaciones derivado de la ocupación de zonas de riesgo y pérdida de la cultura del territorio

El segundo itinerario que se realiza en la Huerta de Alicante tiene como finalidad analizar las relaciones entre el paisaje cultural y el patrimonio hidráulico y las afecciones vinculadas al abandono de las actividades agrarias. Los elementos a visitar son los que configuraron el sistema de riego en este antiguo espacio de regadío, concretamente: a) El sistema de acequias, los azudes de Mutxamel y San Juan (figura 8, superior); b) El Pantanet (balsa de regulación del siglo XIX para el riego de la huerta); c) Antigua zona de marjal donde se evacuaban las aguas muertas o sobrantes del riego (zona de la Condomina); y d) Visita a una casatorre. Estas construcciones defensivas se localizaban en las principales arterias de regadío que, a su vez, coincidían con zonas de cruces de caminos y principales vías de comunicación para el control del paso y regulación de la derivación y uso del agua (Morote y Medina, 2015). Con su realización, se evidencia el proceso de abandono de una antigua área agrícola (figura 8 inferior) y cómo la pérdida de la función agrícola ha conllevado la degradación del rico patrimonio hidráulico, si bien, en los últimos años se han adoptado algunas iniciativas orientadas a su recuperación. 


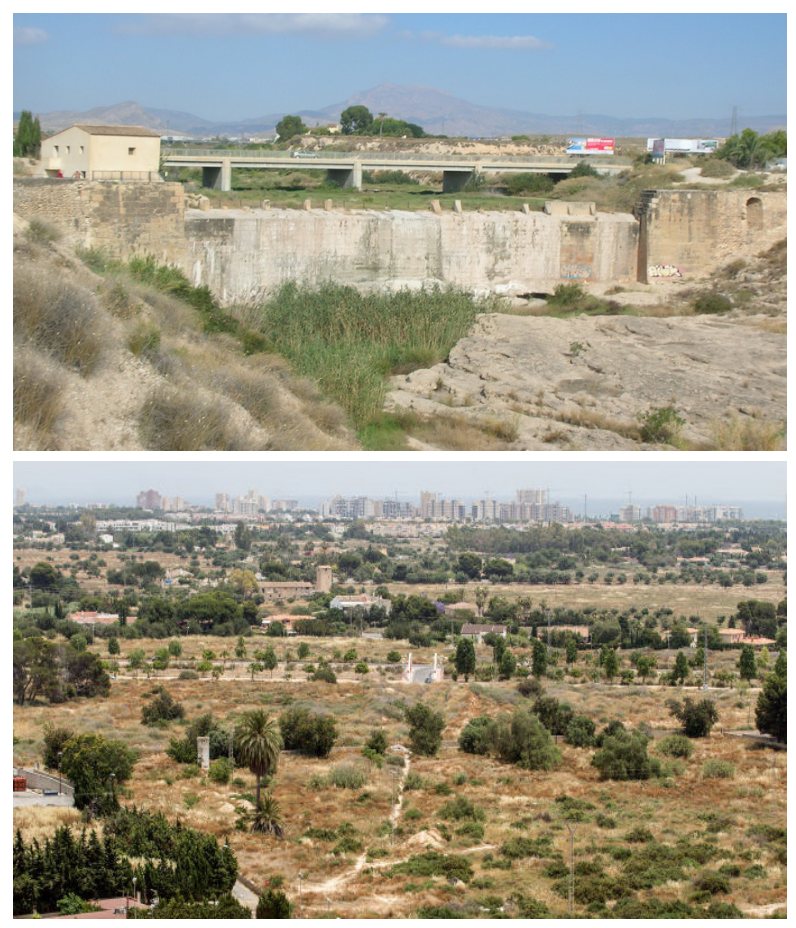

Figura 8. Paisaje actual de la Huerta de Alicante. La imagen superior corresponde al azud de San Juan y la imagen inferior se trata de una panorámica desde lo alto de la Torre de las Rejas. Foto: Autores, junio de 2014 y julio de 2017, respectivamente.

\subsection{SALIDA DE CAMPO POR SAN VICENTE DEL RASPEIG Y ALREDEDORES DEL} CAMPUS DE LA UNIVERSIDAD DE ALICANTE

El objetivo de esta salida de campo es que el alumnado sepa interpretar el territorio y su vulnerabilidad ante un determinado riesgo, en este caso el de inundación. Se circunscribe a la localidad de San Vicente del Raspeig (Alicante), pero los objetivos se pueden extrapolar a otras áreas con características urbanas y físico-ecológicas similares. La idea principal con la que se tienen que quedar los discentes al concluir esta actividad es que, generalmente, en los espacios de riesgo de inundación, gran parte de esta afectación es debida a que ha aumentado la vulnerabilidad y no tanto por la peligrosidad (lluvias intensas). Además, esta propuesta sirve de "laboratorio del territorio" ya que a los/as alumnos/as se les plantea cómo resolver el riesgo de inundación desde el propio conocimiento adquirido en clase (teoría, definiciones, conceptos, resolución de problemas, otros casos de estudio, debates, etc.). 
El itinerario consta de 14 paradas (Figura 9) que comienzan en el Campus Universitario de San Vicente del Raspeig ("aguas abajo") y el recorrido va ascendiendo de cota altimétrica y atravesando la población de San Vicente del Raspeig para analizar los puntos más conflictivos y vulnerables. En el Campus Universitario hay 4 paradas. La idea es que el alumnado tenga la percepción de que esta zona se trata de un área endorreica, con problemas de evacuación de escorrentías pero que, además, se ha incrementado el riesgo al aumentar la vulnerabilidad por actuaciones de origen antropogénico, como pueden ser la construcción de edificios con plantas subterráneas (y sin medios de evacuación), la permeabilización del suelo o la construcción de vías de comunicación a una cota superior que bordean todo el campus lo que dificulta la evacuación de la escorrentía. El resto de paradas (de la 5 a la 14) discurren por el casco urbano de la localidad. En esta parte del recorrido se visitan antiguas infraestructuras hidráulicas de aprovechamiento de turbias (antiguo aljibes) y la deficiente praxis urbana debido a la subida de cota de algunas calzadas. Ello ha repercutido en que en algunos casos las entradas de los edificios se encuentren ahora a una altura inferior que la de la propia calle. También se analiza parte del origen de las causas del incremento de la escorrentía como es el caso del abandono de cultivos en la parte más septentrional del recorrido.

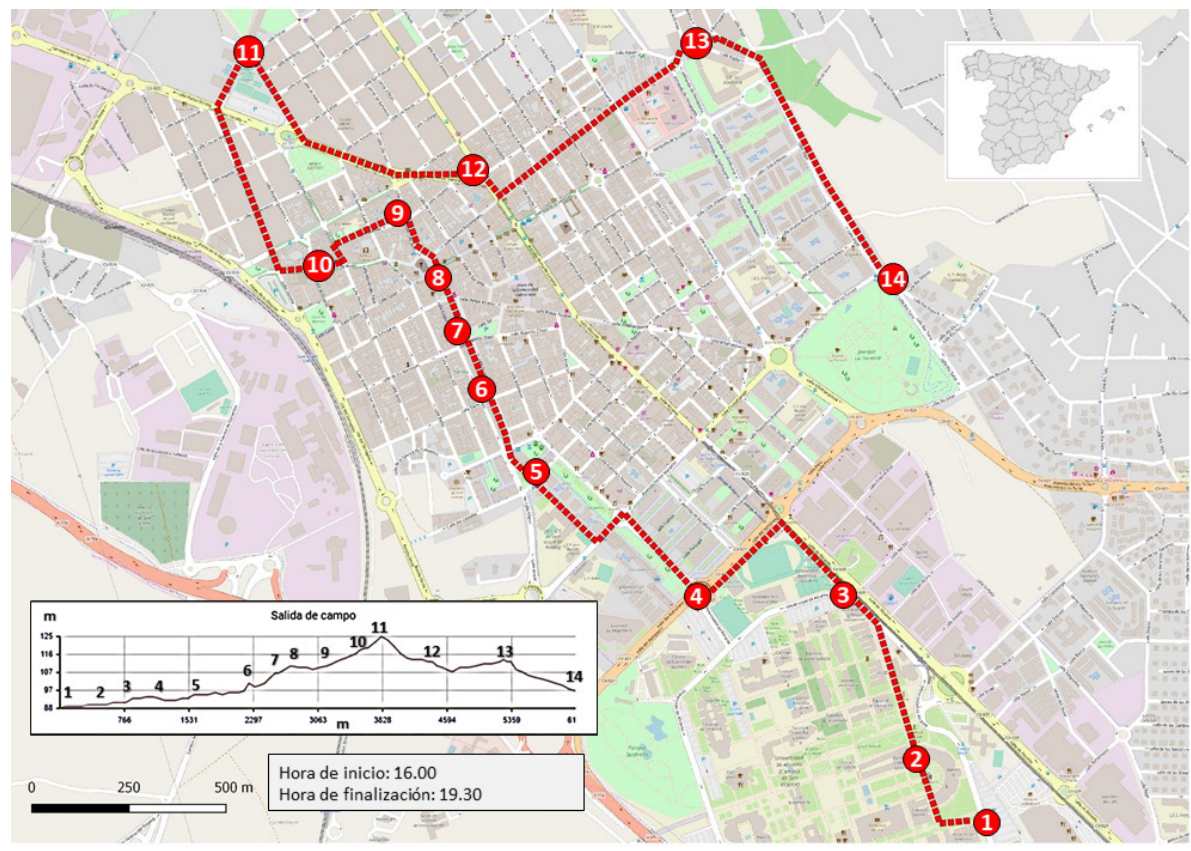

Figura 9. Recorrido de la salida de campo de San Vicente del Raspeig y Campus de la Universidad de Alicante. Fuente: Autores. 


\subsection{LA SALIDA DE CAMPO POR LA MONTAŃA DE ALICANTE}

El principal objetivo de esta salida de campo es señalar que, más allá de los riesgos de inundación del litoral, existen otros vinculados a deslizamientos, por ejemplo, típicos de las zonas de interior y asociados a dos fenómenos casi impensables en la costa, como son los temporales de lluvia prolongados y las nevadas. Aún más importante en esta salida es señalar el hecho de que muchos riesgos que afectan al litoral pueden ser mitigados con una buena gestión del territorio en el interior como el mantenimiento de los paisajes aterrazados, por lo que suponen, más allá del valor estético y cultural, de control de la erosión, laminación de avenidas y función de cortafuegos ante grandes incendios forestales.

Para ello se llevan a cabo varias paradas en municipios que forman parte de la Montaña de Alicante que permiten poner de manifiesto la relación entre los procesos de abandono, intensificación de usos y la acentuación de una serie de riesgos. Concretamente: a) Deslizamientos asociados a la existencia de litologías blandas (margas) y el abandono de cultivos que afecta al polígono industrial Santiago Paya (Alcoi); b) La inestabilización de laderas por la construcción de infraestructuras, concretamente la $\mathrm{A} 7$ a su paso por el término municipal de Cocentaina; y c) Análisis de los rasgos que caracterizan a los paisajes aterrazados asociados al mantenimiento de cultivos tradicionales e introducción de otros nuevos (Planes). La salida concluye con la visita al Museo del Clima en el municipio de Beniarrés. El aprendizaje que ofrece este centro no sólo se enmarca dentro del contexto de la Climatología, sino que lo realmente importante y didáctico es la relación existente entre esta ciencia y su vinculación y manifestación en la sociedad y el territorio de la Montańa de Alicante (Morote y Moltó, 2017). Por lo tanto, una manera interactiva de aumentar el conocimiento de la cultura del territorio de esta parte de la provincia de Alicante.

\section{Conclusiones}

La ordenación de los paisajes en el sureste peninsular, basada en un conocimiento profundo del espacio y su dinámica natural por parte del ser humano permitió adaptarse a las condiciones imperantes en estas tierras y, con ello, aprovechar al máximo cuanto del medio era posible, ejerciendo, al mismo tiempo, prácticas de regulación de las ramblas, laminando y controlando sus crecidas, creando suelos agrícolas con la retención de légamos e incrementando la infiltración en los suelos o conservando estos en las laderas. Con el abandono de estos paisajes (o un porcentaje significativo de las superficies ocupadas por ellos) los beneficios generados por esta ordenación se han traducido ahora en una acentuación de los riesgos socio-ambientales. Estos espacios vuelven a su estado natural o pseudonatural (los bancales se erosionan, las laderas se desestabilizan, los márgenes desaparecen, etc.), o algunos de los elementos que integran estos paisajes (por ejemplo, los canales que distribuyen las aguas de turbia) abandonados 
recuperan parte de su funcionalidad coincidiendo con precipitaciones de cierta intensidad horaria, provocando inundaciones en áreas que antiguamente eran espacios agrícolas y que en la actualidad se han convertido en urbanizaciones. Su abandono, además de la pérdida de recursos patrimoniales y culturales (Hernández y Olcina, 2013), conlleva la desaparición de la capacidad de aprendizaje en el manejo mediante prácticas sostenibles del territorio de las poblaciones locales. Este proceso se ha traducido en una importante pérdida de saberes para gestionar un territorio (Pinto, Gustavsson y Pirnat, 2006).

Paralelamente, a estos procesos de pérdida de saberes y degradación del paisaje por pérdida de funcionalidad en las últimas décadas se ha producido su "redescubrimiento". Este desempeńa un papel fundamental en los valores que las sociedades les asignan, a saber, económico, ambiental y cultural. Las iniciativas orientadas a su conservación desde el punto de vista cultural y económico se han desarrollado, como ha sucedido en la Montaña de Alicante, al amparo de los Programas de Desarrollo Rural, que con diferentes denominaciones se han aplicado ininterrumpidamente desde principios de la década de los años 90, asociadas en un primer momento al desarrollo de actividades turísticas y, posteriormente, con carácter más integrado. A estas iniciativas se han ido incorporando en los últimos ańos actuaciones orientadas a poner en valor las producciones locales en el marco de planteamientos agroecológicos (Hernández et al. 2018). Las actuaciones que se relacionan con su valor ambiental y territorial se vinculan a su mantenimiento dada la minimización de una serie de procesos (pérdida de suelos o laminación de las ondas de crecida) y beneficios ambientales (aumento de la percolación y, por tanto, recarga de acuíferos). En este último se integra el uso sostenible de los recursos hídricos, vinculado al uso de las aguas pluviales que pasan de ser consideradas un riesgo a un recurso. En esta línea se inserta la construcción del parque La Marjal en la playa de San Juan (Alicante). El interés por esos recursos no convencionales se acentúa desde el punto de vista de un uso más sostenible y "circular" de los recursos hídricos, pero también como consecuencia de las previsiones asociadas al cambio climático (una mayor intensidad e irregularidad de las precipitaciones y de los periodos de sequía).

Por último se debe mencionar que la degradación de los paisajes aterrazados y del riego de turbias (secano mejorado) conlleva una notable pérdida patrimonial, es decir, de elementos que reflejan las relaciones de una sociedad con el medio en el que se asienta y que son reflejo de su identidad (Hernández y Molto, 2010; Mata y Fernández, 2019; Gómez y Hervás, 2012). Por esta razón, ambos deberían considerarse como recursos turístico-culturales y educativos, ya que asociados a estos sistemas aparecen un gran número de elementos patrimoniales de interés arquitectónico. Incrementar el conocimiento sobre el significado y transcendencia de estos paisajes entre la población debe ser un objetivo prioritario. Por ello, como se ha puesto de manifiesto en este trabajo con la propuesta de diferentes salidas de 
campo, estos recursos, para el caso del ámbito educativo (en todos sus niveles desde Infantil hasta los postgrados universitarios) pueden contribuir a dar a conocer $y$, más importante, a que los/as discentes sepan interpretar críticamente el territorio que les rodea y sepan valorar los riesgos ambientales asociados a la degradación de los paisajes aquí presentados y los beneficios que conlleva su recuperación y mantenimiento. De los casos de estudio aquí presentados se puede aprender que lograr formar a una sociedad crítica y que sepa entender el territorio en el que vive puede convertirse en un factor de primer orden para reducir la vulnerabilidad frente, en este caso, a los riesgos ambientales y escenarios de cambio climático.

\section{BibLIOGRAFÍA}

Álvarez, D., Vásquez, W.F. y Rodríguez, L.A. (2016). La salida de campo, una posibilidad en la formación inicial docente. Didáctica de las Ciencias Experimentales y Sociales, 3 (2), 61-77.

Arias, J., Gómez, J. y Martínez, E. (2016). La interpretación del paisaje de los humedales como recurso didáctico para la Geografía. En R. García, F. Alonso, F. Belmonte y D. Moreno (Eds.), Retos y Tendencias de la Geografía Ibérica (pp. 441-453). Murcia: Asociación de Geógrafos Españoles.

Asins, S. (2007). Los aterrazamientos mediterráneos, paradigma ambiental-agrocultural. En El paisaje mediterráneo. Opciones de multifuncionalidad (pp. 8191). Madrid: Fundación Santander Central Hispano.

Cebrián, A (2000). Los fondos comunitarios: elemento dinamizador de las Comunidades Autónomas deprimidas. En XVI Reunión de Estudios Regionales (pp. 189-201). San Sebastián: Asociación Española de Ciencia Regional.

Colomar, A. (Ed.) (2002). Patrimonio de bancales en el mediterráneo occidental. Una propuesta de catalogación. Mallorca: Fodesma.

Del Moral, L. (2009). Nuevas tendencias en la gestión del agua, ordenación del territorio e integración de políticas sectoriales. Scripta Nova, 13 (85). Recuperado de http://www.ub.edu/geocrit/sn/sn-285.htm.

Delgado, J. y Rodrigo, J. (2012). El trabajo de campo y las competencias geográficas en el estímulo para el estudio de la geografía: aplicación en un aula de $2^{\circ}$ de Bachillerato. Didáctica Geográfica, 13, 35-56.

Fernández, J. (2017). La salida de campo como recurso didáctico para conocer el espacio geográfico: El caso de la ciudad de Valladolid y de Soria. Didáctica Geográfica, 18, 91-109.

Gil, E, López Fernández, J.A. y Gómez, J. Mª (2015). Regadíos de turbias y secanos asistidos en el Sureste de Espańa. El sistema de azud de Guadalupe o presa de derivación de avenidas de la rambla del Zoco (Murcia). Revista murciana de Antropología, 22, 161-176. 
Giménez, P. (2016). Sobre la aportación y límites de las terrazas de cultivo. Algunas observaciones de campo. En J.F. Vera, J. Olcina y M. Hernández (Eds.), Paisaje, cultura territorial y vivencia de la Geografia. Libro homenaje al profesor Alfredo Morales Gil (pp. 111-124). Alicante: Servicio de Publicaciones de la Universidad de Alicante.

Gómez, J. Ma . y Hervás, R. Ma. (Coords.) (2012). Patrimonio hidráulico y cultura del agua en el Mediterráneo. Murcia: Fundación Séneca y Agencia Española de Cooperación Internacional para el Desarrollo.

Hernández, M. (2009). El paisaje como seña de identidad territorial: valorización social y factores de desarrollo, ¿utopía o realidad?, Boletín de la Asociación de Geógrafos Españoles, 49, 169-184.

Hernández, M. (2010). Terraced landscapes: new uses and dynamics in the Western Mediterranean basin. En G. Robinson, F. Molinero y J. C. Guerra (Eds.), III Anglo-Spanish Rural Geography Conference. Proceedings (pp. 81-94). Madrid: Asociación de Geógrafos Españoles.

Hernández, M. (2011). La huerta de Alicante: un paisaje desarticulado, vivo en la memoria colectiva. En F. Molinero, F.J. Ojeda y J. Torts (Coords.), Los paisajes agrarios de España: caracterización, evolución y tipificación (pp. 289-299). Madrid: Editorial Ministerio de Medio Ambiente, Medio Rural y Marino

Hernández, M. y Olcina, J. (2013). Paisajes culturales y patrimonio hidráulico en tierras valencianas. Claves identificativas y estado de la cuestión. En J. Hermosilla Pla (Ed.), Las galerías de agua en la región noroccidental de Túnez. Patrimonio hidráulico mediterráneo (pp. 9-19). Valencia: Servicio de Publicaciones de la Universidad de Valencia.

Hernández, M. y Moltó, E. (2010). La cultura del agua en ámbitos semiáridos: valores paisajísticos, ambientales y culturales. En F. Leco, A. Pérez B. Mateos, R. García y V. Alberdi (Coords.), Territorio, paisaje y patrimonio rural. XV Coloquio de Geografia Rural (pp. 398-409) Cáceres: Universidad de Extremadura. Servicio de Publicaciones.

Hernández, M., Moltó, E. y A.F. Morote (2018). Las redes agroalimentarias en la Montaña de Alicante, entre la tradición y las expectativas asociadas a la multifuncionalidad de los paisajes. En V. Paül, R. Lois, J. M. Trillo y F. McKenzie (Coords.), Infinite rural systems in a finite planet: bridging gaps towards sustainability (pp. 43-50). Santiago de Compostela: Universidad de Santiago de Compostela y UGI.

Hernández, M. y Morales, A. (2013). Los aprovechamientos tradicionales de las aguas de turbias en los piedemontes del sureste de la península Ibérica: estado actual en tierras alicantinas. Boletín de la Asociación de Geógrafos Españoles, 63, $105-123$. 
Hernández, M., Saurí, S. y Moltó, E. (2016), Las aguas pluviales y de tormenta: del abandono de un recurso hídrico con finalidad agrícola a su implantación como recurso no convencional en ámbitos urbanos". En J.F. Vera, J. Olcina y M. Hernández (Eds.), Paisaje, cultura territorial y vivencia de la Geografía. Libro Homenaje al profesor Alfredo Morales Gil (pp. 1099-1120). Alicante, Servicio de Publicaciones de la Universidad de Alicante.

Klein, D., Baquero, R. A. y Clough, Y. (2006). Mixed biodiversity, benefits of agri-environment schemes in five European countries. Ecology Letters, 9 (3), 243-254

Lasanta, T. (2007). El paisaje de la montaña mediterránea. Cambios por el abandono de tierras agrícolas. En El paisaje mediterráneo. Opciones de multifuncionalidad (pp. 58-69), Madrid: Fundación Santander Central Hispano.

López Gómez, A. (1951). Riegos y cultivos en la Huerta de Alicante. Estudios Geográficos, 41, 701-771.

López Bermúdez, F. (2014). El riego por boquera en agricultura de secano, técnica hidráulica tradicional de lucha contra la desertificación en el Sureste Ibérico semiárido. En J. Arnáez, P. González, T. Lasanta y B. Valero (Eds.), Geoecología, cambio ambiental y paisaje. Homenaje al profesor José María García Ruiz (pp. 405-413). Madrid: Universidad de La Rioja y CSIC.

Marco, J. A. y Morales, A. (1995). Terrazas de cultivo abandonadas en el sureste peninsular. Investigaciones Geográficas, 13, 81-90.

Marco, J. A. y J.F. Vera (1988). Impactos de los usos del suelo y erosión en las cuencas vertientes del sur del País Valenciano. Investigaciones Geográficas, 6, 7-32.

Mata, R. (2004). Agricultura, paisaje y gestión del territorio. Polígonos. Revista de Geografía, 14, 97-137.

Mata, R., De Meer, A. y De la Puente, L. (2012). Sustainable development and the making of territory and everyday landscapes as heritage an experience in the Cantabrian mountains. En J.Ma. Feria (Ed.), Territorial heritage and development (pp. 141-159). Londres: Taylor and Francis.

Mata, R. y Fernández, S. (2010). Paisajes y patrimonios culturales del agua. La salvaguarda del valor patrimonial de los regadíos tradicionales. Scripta Nova, XIV (337). Recuperado de http://www.ub.edu/geocrit/sn/sn-337.htm

Moltó, E. y Hernández, M. (2012). La subexplotación de los paisajes culturales y su incidencia en los riesgos naturales. Una propuesta metodológica. En E. Araque, R. Baena, C. Delgado et al. (Eds.), Investigando en Rural (pp. 483491). Sevilla: Asociación de Geógrafos Españoles. 
Moltó, E. y Hernández, M. (2018). Los sistemas participativos de garantía como alternativa a la certificación ecológica oficial. en E. Cejudo, F.A. Navarro y J.A. Camacho (Eds.), Nuevas realidades rurales en tiempos de crisis: territorios, actores, procesos y politicas (pp. 495-507). Granada: Editorial Universidad de Granada.

Mondéjar, J.M. (2010). El riego de boqueras: una técnica hidráulica para la gestión ambiental de territorios semiáridos y lucha contra la desertificación. Aprovechamientos tradicionales de aguas de escorrentía en las cuencas de la comarca de l'Alacantí (Tesis doctoral no publicada). Alicante: Universidad de Alicante.

Mongil, J. y Martínez de Azagra, A. (2007). Técnicas de recolección de agua y de oasificación para el desarrollo de la agricultura y la restauración forestal en regiones desfavorecidas. Cuadernos Geográficos, 40, 67-80.

Mongil, J., Martínez de Azagra, A. Sánchez, M.E. y García, M. (2009). Sistemas tradicionales de recolección de escorrentía en laderas. En J. Navarro, A. Martínez de Azagra y J. Mongil (Coords.), Hidrología de conservación de aguas. Captación de precipitaciones horizontales y escorrentias en zonas secas (pp. 77 115). Valladolid: Servicio de Publicaciones de la Universidad de Valladolid.

Morales, A. (1969). El riego con aguas de avenida en las laderas subáridas. Papeles del Departamento de Geografía, 1, 167-183.

Morales, A. (1974). Tres ejemplos de centuriatio en el Altiplano de JumillaYecla. En V. Roselló (Ed.), Estudio de las centuriaciones en España (pp. 69-82). Madrid: Universidad Autónoma de Madrid.

Morales, A. (1986). Abandono y desorganización de los sistemas de riegos de turbias. Su incidencia en la escorrentía. En Los paisajes del agua. Libro jubilar dedicado al profesor Antonio López Gómez (pp. 199-204). Valencia: Universidad de Valencia y Universidad de Alicante.

Morales, A. y Box, M. (1986). El aprovechamiento del agua y los suelos en un dominio semiárido: la cuenca del barranco Blanco. Agost. (Alicante). Investigaciones geográficas, 4, 7-24.

Morales, A. y Box, M. (1996). Boqueras y Azudes: el aprovechamiento exhaustivo de las aguas esporádicas en el sureste peninsular. En Cuatro siglos de técnicas hidráulicas en tierras alicantinas (pp. 31-41). Alicante: Instituto de Cultura "Juan Gil-Albert".

Morales, A. y Hernández, M. (2018). Aproximación epistemológica sobre los usos de agua de avenida en las laderas subáridas. En J.A. Márquez y R. Ma Jordá (Eds.), Ciencia Regional y Andalucía a partir de la visión del geógrafo Gabriel Marco Cano García. Un homenaje a su vida y obra (pp. 279-298). Sevilla: Servicio de Publicaciones de la Universidad de Sevilla. 
Morote, A.F. (2013). El aprovechamiento de turbias en San Vicente del Raspeig (Alicante) como ejemplo de sistema de riego tradicional y sostenible. Investigaciones Geográficas, 59, 147-169.

Morote, A.F. (2014). El aprovechamiento de turbias en l'Alacantí (Alicante): una gestión sostenible del agua y protección del patrimonio rural". En D. Pavón, A. Ribas, S. Ricart, A. Roca, I. Salamaña y C. Tous (Eds), Revalorizando el paisaje rural: leer el pasado para ganar el futuro. XVII Coloquio de Geografia rural (pp. 413-423). Girona: Documenta Universitaria.

Morote, A.F. (2017). El Parque Inundable La Marjal de Alicante (España) como propuesta didáctica para la interpretación de los espacios de riesgo de inundación. Didáctica Geográfica, 18, 211-230.

Morote, A.F y M. Hernández (2017). El uso de aguas pluviales en la ciudad de Alicante. De Viejas ideas a nuevos enfoques. Papeles de Geografía, 63, 7-25.

Morote, A.F y Medina, R.E. (2015). La Huerta de Alicante y sus torres de defensa: Propuesta de una ruta turística. Cuadernos de Turismo, 35, 287-309.

Morote, A.F. y Moltó, E. (2017). El Museo del Clima de Beniarrés (Alicante). Propuesta de un recurso didáctico para la enseñanza de la Climatología. Didáctica de las Ciencias Experimentales y Sociales, 32 (1), 109-131.

Nogué, J. (2016). El reencuentro con el lugar: nuevas realidades, nuevos paisajes y cambio de paradigma. Documents d'Anàlisi Geogràfica, 63 (2), 489-502.

Olcina, J. (2013). Experiences in adapting to Climate Change and Climate Risk in Spain. En Ph Schmidt-Thomé y J. Klein (Eds.), Climate Change Adaptation in practice: from strategy development to implementation (pp. 253-268). New Yersey: Wiley-Blackwell.

Ojeda, J.F. (2013). Lectura transdisciplinar de paisajes cotidianos, hacia una valoración patrimonial. Método de aproximación. Revista invi, 28 (78), 27 75.

Ojeda, J.F. (2015). Percepciones identitarias y creativas de los paisajes mariánicos. Scripta Nova, 9 (187). Recuperado de http://www.ub.edu/geocrit/sn/sn-187. htm.

Palerm, J. (Ed.) (2002). Introducción. En J. Palerm (Ed.), Antología sobre Pequeño Riego. Sistemas de riego no convencionales, vol. III (pp.1-20). México D.F., Colegio de Postgraduados.

Pérez, A. (2008). Aumento del riesgo de inundación por ocupación indebida de las áreas de convergencia de aguas en el sur de la región de Murcia. Scripta Nova, 270 (27), Recuperado de http://www.ub.edu/geocrit/sn/sn-270/sn270-27.htm. 
Pint, T., Gustavsson, R y Pirnat, J. (2006). Bringing the gap between centrally defined policies and local decisions. Towards more sensitive and creative rural landscape management. Landscape ecology, 21, 333-34.

Souto, X. M. (2007). Educación Geográfica y Ciudadanía. Didáctica Geográfica, 9, 11-32.

Zoido, F. (2012). El paisaje, un concepto útil para relacionar estética, ética y política. Scripta Nova, 16 (407). Recuperado de http://www.ub.es/geocrit/sn/ sn-407.htm.

Zoido, F. (2016). El paisaje, fundamento de un buen gobierno del territorio. Boletín de la Institución Libre de Enseñanza, 202-203, 41-60. 
